\title{
A Precision Planter for Seedling Emergence Evaluation
}

\author{
G.W. FRASIER
}

\section{Abstract}

A modified version of the laboratory vacuum plate seed counter was developed for precision planting of small seeds in soil. The planter, a vacuum chamber constructed from rigid plastic plate, would place 100 seeds on a $228 \times 228 \mathrm{~mm}$ plot. The individual seed holders were hypodermic needles inserted into the bottom of the chamber on a square grid at a $25 \mathrm{~mm}$ spacing. When a vacuum was applied to the chamber, a single seed was held at the tip of each needle. Seedbed preparation consisted of forming small impressions in the soil surface with a grid spacing identical to the planter. With the planter properly aligned, a single seed was dropped into each impression. This technique was successfully used with seeds ranging in size and shape of Panicum antidotale Retz to Eragrostis lehmanniana Nees. Three people were able to seed 120 plots with 100 seeds in less than 4 hours.

To accurately determine the germination characteristics of seeds, it is necessary to place a specific number of seeds on a germination surface and observe the number of seedlings produced. Laboratory germination studies on blotter or filter paper germinating surfaces are relatively simpler to conduct, but the results may not accurately depict what happens in a soil media where moisture and nutrients may be less than optimum. Germination and initial seedling emergence studies in the field can provide more realistic results.

Counting and placement of small seeds on field plots by hand is a slow, tedious process. In routine laboratory blotter or filter paper germination tests, vacuum plate counters are often used for seed counting and placement. These counters are simply metal plates perforated with small holes on a special grid spacing. The holes are interconnected on the plate back with a flexible tubing to a vacuum pump. To operate, the plate is positioned upside down, the vacuum turned on, and a layer of seeds placed on the surface. The seeds are moved over the surface by light tipping of the plate until each hole

\footnotetext{
Author is research hydraulic engineer, Southwest Rangeland Watershed Research Center, ARS-USDA, 2000 East Allen Road, Tucson, Arizona 85719

The author wishes to thank Art Dolphin, machinist, for his assistance and suggestions during construction and evaluation of the planter.

Manuscript accepted May 21, 1984.
}

is covered by a single seed. The excess seeds are dumped off, and the plate positioned above the germinating surface. Turning the vacuum off releases the seeds. These plate counters are not designed to operatc under field conditions of irregular surfaces and where the plots may be some distance apart. A modified version of the vacuum plate seed holder was constructed and successfully used for precision planting of grass seeds in the field.

\section{Materials and Methods}

\section{Seed Holder-Planter:}

The seed planter constructed would seed a plot $228 \times 228 \mathrm{~mm}(9$ in $\times 9$ inches) with 100 seeds spaced $25 \mathrm{~mm}$ ( 1 inch) apart on a square grid. The top and bottom of the planter was $305 \times 305 \mathrm{~mm}$, made from $6 \mathrm{~mm}$ thick, clear, rigid plastic plate (Fig. 1). An air-tight chamber, $25 \mathrm{~mm}$ deep, was formed between the plates by bonding $6 \mathrm{~mm}$ thick plastic strips around the sides. Spacers were inserted between the plates to prevent flexing and cracking of the top and bottom plates. The bottom plate was perforated with 100 holes, $0.36 \mathrm{~mm}$ in diameter, and a $15-\mathrm{mm}$ length of stainless steel

Table 1. Mean and standard deviation of 20 tests per species of the number of seeds loaded onto planter.

\begin{tabular}{lrc}
\hline \hline & \multicolumn{2}{c}{ Seed count } \\
\cline { 2 - 3 } Grass species & Mean & Standard deviation \\
\hline Panicum antidotale & 96.0 & 4.01 \\
Eragrostis curvula & 100.8 & 6.51 \\
Eragrostis lehmanniana & 117.1 & 13.59 \\
Eragrostis lehmanniana & & \\
$\quad$ E. trichophora & 107.8 & 11.27 \\
Bouteloua curtipendulat & 90.5 & 11.56 \\
\hline
\end{tabular}

'Dehulled 


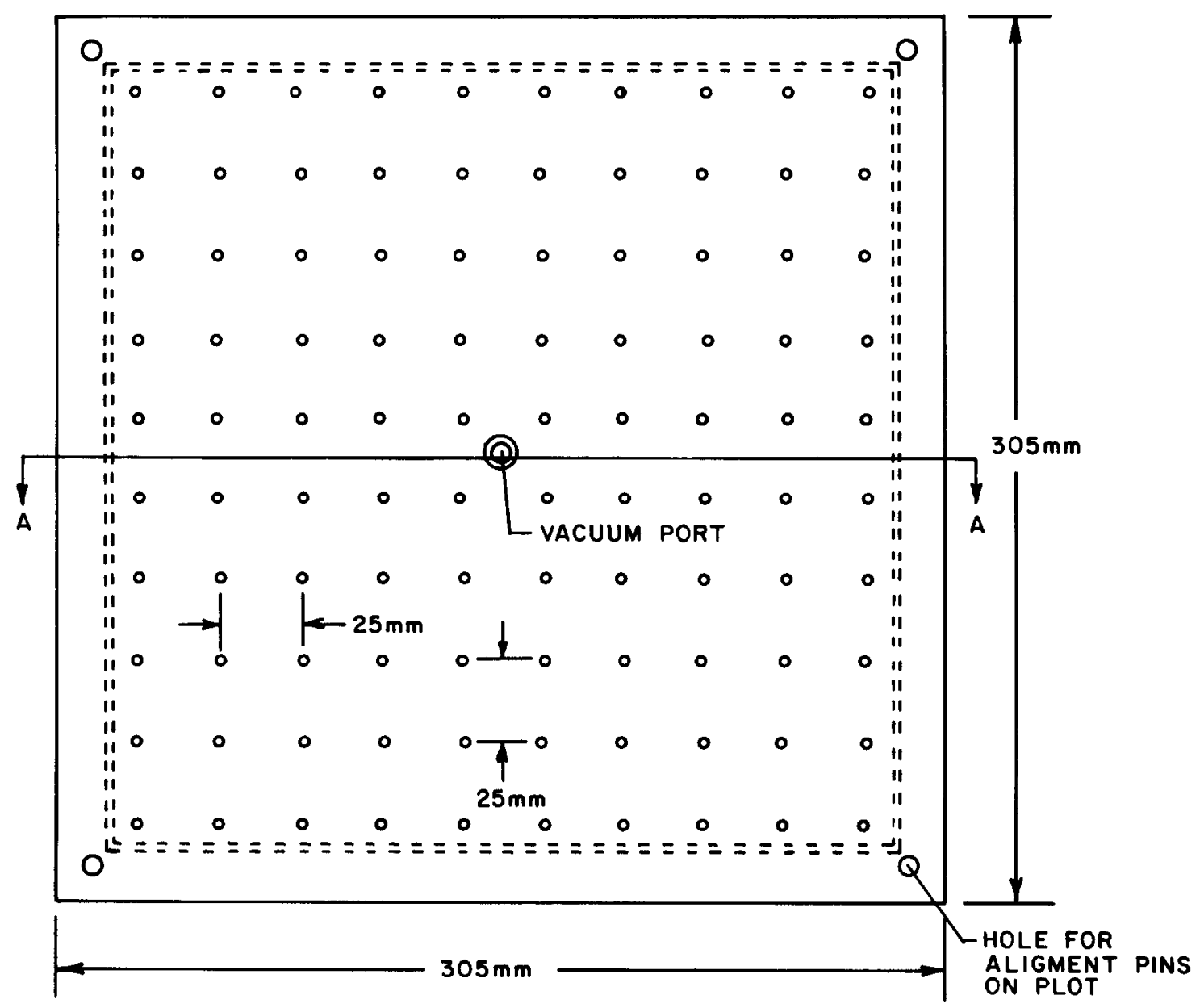

PLANTER TOP VIEW

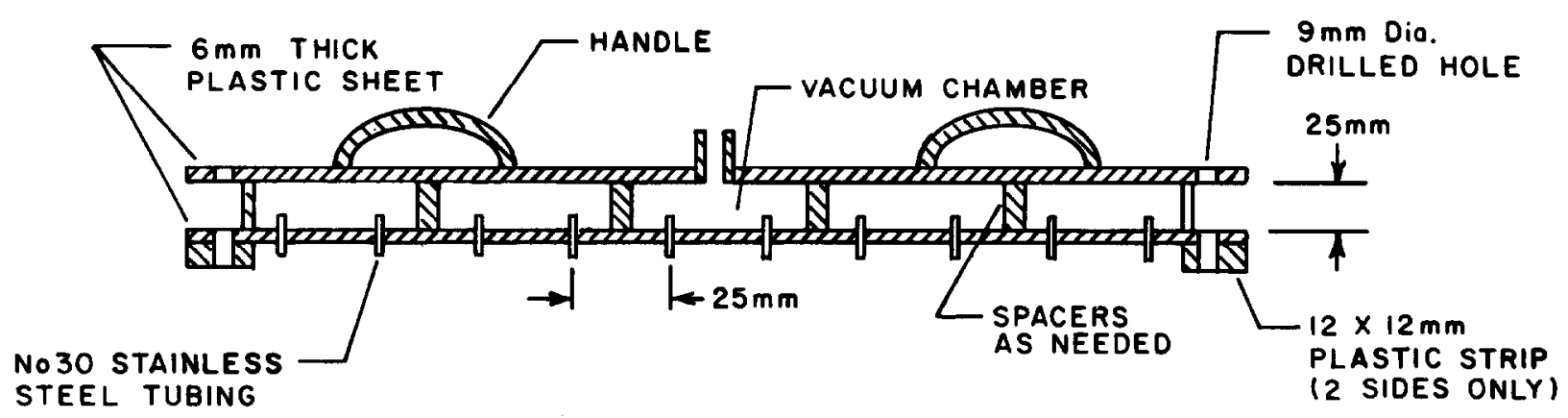

PLANTER CROSS-SECTION A-A

Fig. 1. Sketch of precision plot planter.

tubing, 0.15-mm ID $\times 0.30-\mathrm{mm}$ OD (No. 30 hypodermic needles), inserted and glued in each hole. Five millimeters of tubing was left extending below the plate. To support the planter above the surface and prevent damage to the tubes, a $12 \times 12 \mathrm{~mm}$ plastic strip was bonded to the underside edge of the bottom plate. Holes, $9 \mathrm{~mm}$ in diameter, were drilled in each corner for positioning the planter over alignment pins. The top plate was fitted with handles and a vacuum line connection.
Impression Plate:

A separate plate for making depressions in the soil for seed placement was constructed from $12 \mathrm{~mm}$ thick rigid plastic sheeting. Impression pegs of $9 \mathrm{~mm}$ diameter plastic rods were bonded to the underside of the plate on a $25 \mathrm{~mm}$ spacing, matching the grid spacing of the planter (Fig. 2). The pegs, $6 \mathrm{~mm}$ long, were sharpened to a point. A $12 \times 12 \mathrm{~mm}$ plastic reinforcing strip was bonded around the top edge of the plate. Plate alignment holes, 9 $\mathrm{mm}$ in diameter, were drilled in each corner of the plate. 


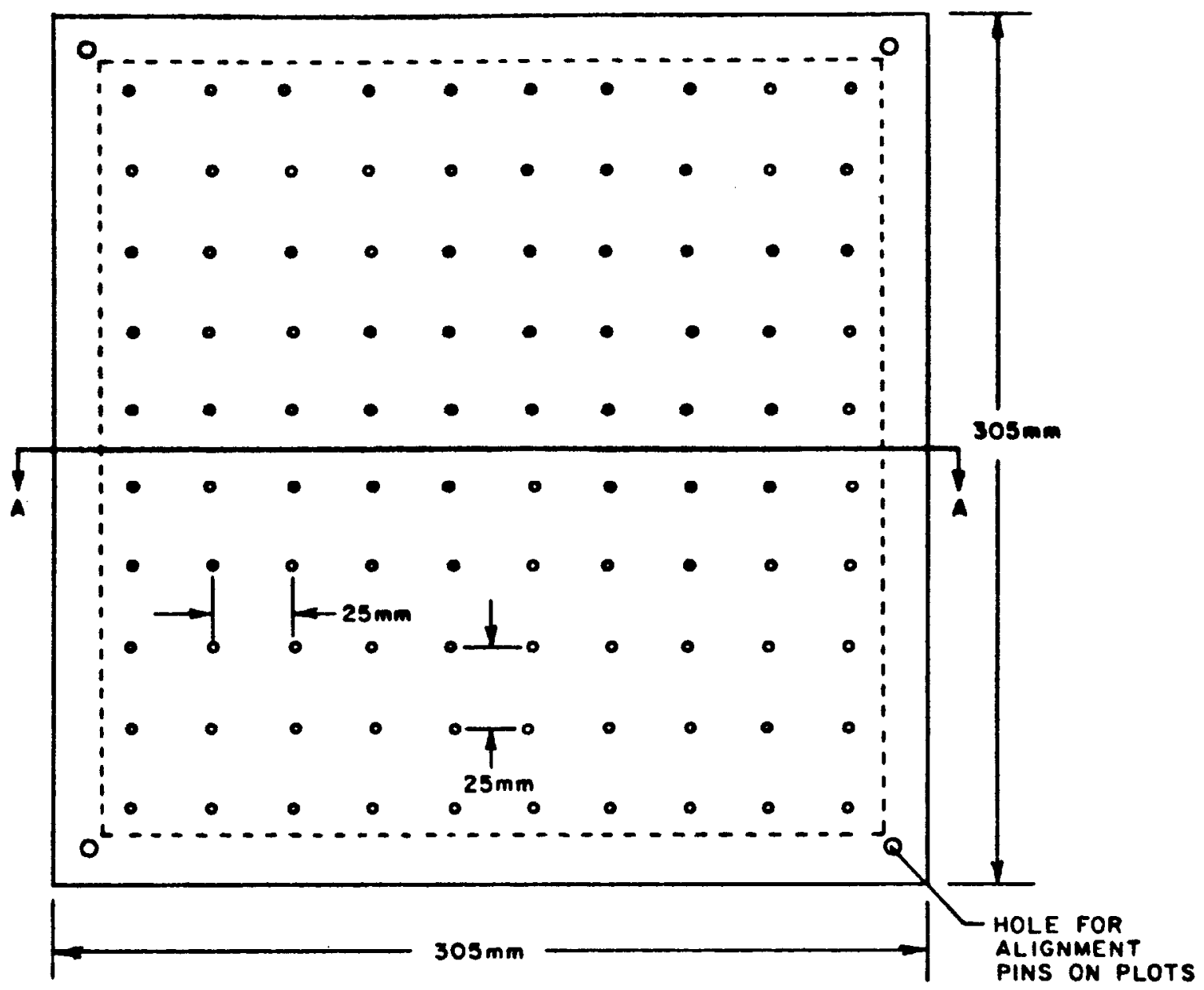

IMPRESSION PLATE TOP VIEW

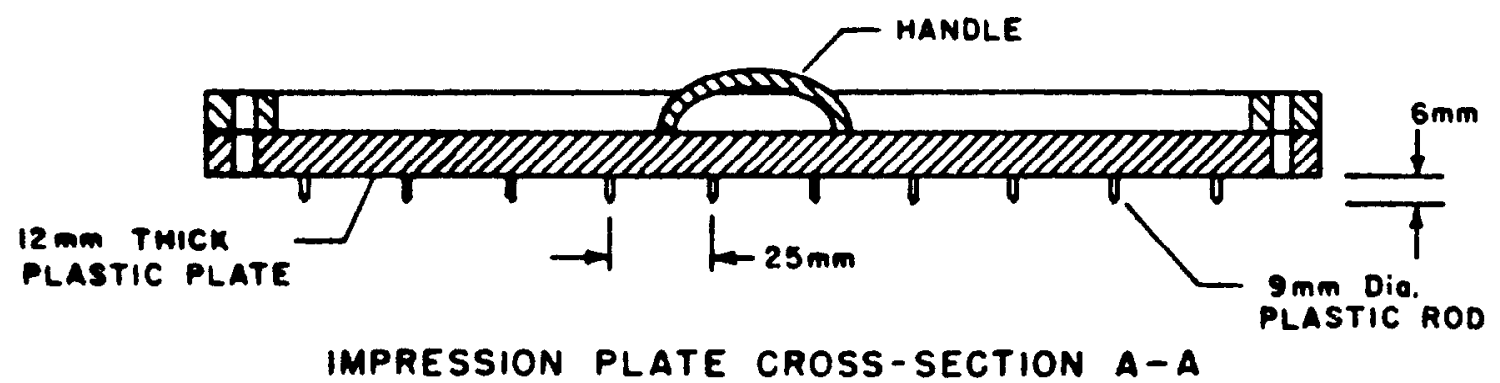

Fig. 2. Sketch of impression plate.

\section{Discussion}

The planter was designed for one seed to be held by each tube. To load all 100 tubes, the planter was placed on a support stand about $300 \mathrm{~mm}$ above the work table. A shallow tray, filled with seeds, was placed under the planter, with the seeds touching each tube tip. When a vacuum was applied $(600 \mathrm{~mm}$ of $\mathrm{Hg}, 1200 \mathrm{cc} / \mathrm{min})$, the closest seed was firmly held at each tube tip. Sometimes, more than one seed was held to a single tube. Usually, light tapping on the top of the planter would dislodge the extra seeds. With practice, the 100-tube planter could be loaded with seeds in 30 to 45 seconds.
Turning the vacuum off released the seeds.

The counting efficiency of the planter was evaluated by repetative loading with a single species and counting the actual number of seeds placed on a counting grid. Table 1 presents the results of 20 replications with 5 grass species. The mean number of seeds varied from 90.5 for dehulled Bouteloua curtipendula to 117.1 for Eragrostis lehmanniana. Seed cleaning was an essential factor. Otherwise, problems were encountered with seed chaff plugging the tubes. Plugged tubes were opened by inserting steel pen cleaner wires through the tubes. 
The planter was used to seed small plots in four separate field studies. Each study consisted of 120 separate plots. The plot area was cleared, leveled, and smoothed. Alignment pins for the impression plate and planter (headless nails $8.5 \mathrm{~mm}$ dia, $100 \mathrm{~mm}$ long) were placed at the corner of each plot with a template. The soil was sprinkled with approximately $6 \mathrm{~mm}$ of water. The impression plate was placed on the plot and weighted to push the impression pegs into the soil surface. Simple pushing or standing on the plate was sufficient to fully push the pegs into the soil. The loaded seed planter was then positioned on the plot and the vacuum released, dropping the seeds into the performed impressions. A couple of light taps on the top of the planter insured that all seeds were dropped. A shallow layer of soil was then sprinkled over the plot to cover the seeds. A 15 -meter plastic hose from the vacuum pump to the planter allowed for easy movement from the work table to the plots. Three people was able to imprint, plant, and cover the 120 plots in $3.5 \mathrm{hrs}$. The precision planting and a counting grid template permitted early detection of seedlings as they emerged from the soil. This technique made it possible to locate new seedlings as little as 1 to $2 \mathrm{~mm}$ in height.

The planter was considered a successful tool in our studies. There are probably improvements which could be incoporated. Different tube diameters and vacuum flow rates, designed for specific seed sizes, may reduce the variation in actual seed counts we experienced. 